\title{
Pengelolaan Tanaman Karet (Hevea brasiliensis Muell. Arg) di Sumatera Utara dengan Aspek Khusus Pembibitan
}

\section{Crop Management Rubber ( $\underline{\text { Hevea }}$ brasiliensis Muell. Arg) in North Sumatra With Special Aspects of Nursery}

\author{
Radhiya Nur Anwar dan Suwarto* \\ Departemen Agronomi dan Hortikultura, Fakultas Pertanian, Institut Pertanian Bogor \\ (Bogor Agricultural University), Jl. Meranti, Kampus IPB Darmaga, Bogor 16680, Indonesia \\ Telp. \& Faks.62-251-8629353 e-mail agronipb@indo.net.id \\ *Penulis untuk korespondensi: wrtskm@yahoo.com
}

Disetujui 18 Januari 2016/ Published online 25 Januari 2016

\begin{abstract}
Internship activities start from February to June 2014 in Dolok merangir, North Sumatra. In 2025 Indonesia aims to be the largest natural rubber producing countries in the world with a production of 3.84.0 million tons year ${ }^{-1}$. Indonesian rubber productivity in 2012 was $1073 \mathrm{~kg} \mathrm{ha}^{-1}$. Productivity can be increased if the plant area which less productive rejuvenated by superior clones. Nursery in rubber influenced by budding activities. The observations aimed to determine the factors which affect of success budding. The result was tested by statistical data analysis f-test. The results showed that a higher percentage of successful budding rootstock on condition of being dormant. The percentage of budding success was highest in clones $P B 260$ (86.12\%) with an average shoot growth of $12.24 \mathrm{~cm} \mathrm{month} \mathrm{c}^{-1}$ and the percentage of budding success was less in clones DMI 35 (48.31\%). The best time for budding on the rubber plant at 7:00 to 9:00 pm because low of transpiration and low light intensity.
\end{abstract}

Keywords: budding, clone, nursery, rubber

\section{ABSTRAK}

Kegiatan magang dilaksanakan pada bulan Februari sampai Juni 2014 di kebun dolok merangir Sumatera Utara. Pada tahun 2025 Indonesia menargetkan menjadi negara penghasil karet alam terbesar di dunia dengan produksi 3.8-4.0 juta ton tahun ${ }^{-1}$. Produktivitas karet Indonesia pada tahun 2012 adalah 1 $073 \mathrm{~kg} \mathrm{ha}^{-1}$. Produktivitas dapat meningkat jika areal tanaman yang saat ini kurang produktif diremajakan menggunakan klon unggul. Pembibitan pada tanaman karet dipengaruhi oleh kegiatan okulasi. Pengamatan yang dilakukan bertujuan untuk mengetahui faktor-faktor yang dapat mempengaruhi keberhasilan okulasi. Hasil pengamatan diuji menggunakan analisis data statistika yaitu uji $f$. Hasil analisis menunjukkan bahwa persentase keberhasilan okulasi lebih tinggi pada kondisi batang bawah yang sedang dorman. Persentase keberhasilan okulasi tertinggi terdapat pada klon PB 260 (86.12\%) dengan rata-rata pertumbuhan tunas $12.24 \mathrm{~cm}_{\text {bulan }}^{-1}$ dan persentase keberhasilan okulasi terendah yaitu pada klon DMI 35 (48.31\%). Waktu yang terbaik untuk melakukan okulasi pada tanaman karet adalah pada pukul 07.00-09.00 WIB karena transpirasi dan intensitas cahaya matahari rendah.

Kata kunci: karet, klon, okulasi, pembibitan 


\section{PENDAHULUAN}

Karet (Hevea brasiliensis Muell. Arg) merupakan salah satu komoditas perkebunan yang penting baik untuk lingkup Indonesia maupun bagi internasional. Indonesia pernah menguasai produksi karet dunia dengan mengungguli produksi negara-negara lain. Tanaman karet merupakan salah satu komoditi perkebunan yang menduduki posisi cukup penting sebagai sumber devisa non migas bagi Indonesia. Luas areal karet Indonesia saat ini, 85\% (2.8 juta ha) merupakan areal perkebunan karet rakyat yang memberikan kontribusi $81 \%$ terhadap produksi karet alam nasional (Balit Sumbawa, 2009).

Secara keseluruhan, luas pertanaman karet di Indonesia dari tahun 1995 hingga tahun 2012 cenderung fluktuatif, tetapi pada tahun 2012 menunjukkan peningkatan yang cukup signifikan. T ahun 2012, Indonesia memiliki perkebunan karet seluas 3506201 ha dengan produksi mencapai $3012 \quad 254$ ton dan produktivitas $1073 \mathrm{~kg} \mathrm{ha}^{-1}$ (Ditjenbun 2013). Pada tahun 2025, Indonesia menargetkan menjadi negara penghasil karet alam terbesar di dunia dengan produksi 3.8-4.0 juta ton tahun $^{-1}$. Permasalahan utama karet Indonesia adalah produktivitas dan mutu karet rakyat yang sangat rendah. Peningkatan produksi dapat dicapai jika areal kebun karet (rakyat) yang saat ini kurang produktif dapat diremajakan dengan menggunakan klon karet unggul sehingga produktivitas rata-rata naik minimal $1500 \mathrm{~kg} \mathrm{ha}^{-1}$ (Anwar, 2007). Penggunaan bibit dari klon unggul dapat meningkatkan produktivitas rata-rata kebun dari $1400-2000 \mathrm{~kg} \mathrm{ha}^{-1} \operatorname{tahun}^{-1}$ menjadi $3500 \mathrm{~kg} \mathrm{ha}^{-1}$ tahun $^{-1}$ (Balit Sumbawa, 2009).

Perbaikan teknologi budi daya juga dapat menjadi salah satu usaha dalam meningkatkan produksi karet di Indonesia. Persiapan pembibitan merupakan aspek budi daya yang sangat penting dilakukan sebelum tanaman menghasilkan menjadi tua dan kurang produktif atau umur ekonomisnya habis. Perbanyakan vegetatif mempunyai peranan yang penting dalam budi daya tanaman perkebunan karena akan menghasilkan tanaman yang secara genetik sama dengan induknya, sehingga memiliki sifat-sifat yang hampir seragam serta memiliki kemampuan produksi yang merata. Keseragaman ini akan meningkatkan efisiensi manajemen pengelolaan perkebunan (Boerhendhy dan Amypalupy, 2010). Penyediaan bibit tanaman karet umumnya dilakukan melalui perbanyakan vegetatif terutama menggunakan teknik okulasi. Kendala yang terdapat dalam teknik okulasi tanaman karet diantaranya adalah penggunaan klon unggul belum optimal dan pemilihan teknik okulasi yang belum sesuai. Oleh karena itu pengamatan aspek-aspek yang mempengaruhi keberhasilan okulasi perlu dilakukan.

Tujuan magang secara umum untuk meningkatkan relevansi atau kesesuaian antara proses pendidikan dengan lapangan pekerjaan serta meningkatkan kemampuan mahasiswa dalam memahami aspek teknis maupun aspek manajemen dalam proses pengelolaan tanaman karet di lapangan. Tujuan secara khusus yaitu untuk mempelajari dan mengetahui pengelolaan aspek pembibitan tanaman karet terutama faktorfaktor yang mempengaruhi keberhasilan okulasi.

\section{BAHAN DAN METODE}

Kegiatan magang dilaksanakan di perkebunan karet, Kabupaten Simalungun, Sumatera Utara. Kegiatan magang ini dilaksanakan selama 4 bulan dari bulan Februari sampai bulan Juni 2014.

Kegiatan magang ini dilaksanakan dengan mengikuti kegiatan teknis dan kegiatan manajerial. Kegiatan teknis dilakukan untuk mendapatkan keterampilan teknis. Kegiatan yang dilakukan adalah menjadi karyawan harian lepas (KHL) selama 1 bulan mengikuti kegiatan sesuai dengan yang dilaksanakan di lapangan. Kegiatan-kegiatan teknis yang dilakukan antara lain pembibitan, pemupukan, pengendalian gulma, penyadapan, aplikasi stimulansia, dan lainlain. Kegiatan manajerial dilakukan sebagai pendamping mandor selama 2 bulan, sebagai pendamping sinder Sub-Divisi selama 1 bulan, dan penyusunan laporan serta membantu dalam kegiatan administrasi kebun untuk memperoleh keterampilan di tingkat manajerial.

Aspek khusus yang diambil sebagai bahan analisis yaitu mengenai pembibitan tanaman karet. Pengumpulan data yang diperlukan terdiri atas data primer dan data sekunder. Data primer diperoleh dengan mengamati parameter keberhasilan okulasi yaitu (1) persentase keberhasilan okulasi pada berbagai kondisi batang bawah, (2) persentase keberhasilan okulasi antar klon, (3) persentase keberhasilan okulasi pada berbagai waktu okulasi, (4) pengamatan pertumbuhan tunas hasil okulasi, dan (5) pengamatan pertumbuhan tanaman menghasilkan. Metode tidak langsung dilakukan dengan studi pustaka dan pengumpulan data sekunder dari arsip perkebunan yaitu data-data keadaan umum perusahaan dan kebun antara lain luas areal, curah hujan, iklim, konsesi dan tata guna lahan, keadaaan tanaman (umur tanam, populasi tanaman, jenis klon tanaman), struktur 
organisasi dan ketenagakerjaan (jumlah pekerja, keterampilan pekerja, dan standar hari kerja), peta lokasi, peta sebaran populasi, data produktivitas dari masing-masing klon yang ditanam, dan data sebaran populasi klon di tiap blok. Selain itu, studi pustaka dilakukan melalui laporan penelitian, jurnal, buku teks, dan sumber pustaka yang lain.

Pengamatan pada aspek khusus pembibitan tanaman karet dalam kegiatan magang sebagai data primer yang dikumpulkan terdapat beberapa parameter khusus yang diamati, yaitu:

1. Pengamatan persentase keberhasilan okulasi pada berbagai kondisi batang bawah. Pengamatan terdiri atas 3 ulangan pada hari yang berbeda dan juru okulasi yang sama. Setiap ulangan terdiri dari 35 tanaman contoh pada kondisi daun batang bawah yang sedang flush dan dorman, sehingga terdapat 210 satuan pengamatan.

2. Pengamatan persentase keberhasilan okulasi pada 5 klon (PB 260, PB 330, PB 340, DMI 13, DMI 35) yang diperoleh dari pemerikasaan okulasi pada kontrol ke-2. Pengamatan terdiri atas 3 ulangan pada bedeng yang berbeda dan juru okulasi yang sama. Setiap ulangan terdiri dari \pm 275 tanaman contoh, sehingga terdapat 4125 satuan percobaan.

3. Pengamatan tanaman contoh pada 3 waktu berbeda yaitu pada pukul 07.00-09.00, 09.00-11.00, dan 11.00-13.00 WIB. Pengamatan terdiri atas 3 ulangan pada bedeng yang berbeda dan juru okulasi yang sama. Setiap ulangan terdiri atas \pm 450 tanaman contoh, sehingga terdapat 4050 satuan percobaan.

4. Pengamatan pertumbuhan tunas hasil okulasi pada 5 klon (PB 260, PB 330, PB 340, DMI 13, DMI 35). Parameter yang diamati adalah tinggi tanaman dan jumlah daun pada 1 bulan dan 2 bulan setelah dilakukan penyerongan (cutback), kemudian dirata-ratakan. Pengamatan terdiri atas 3 ulangan pada bedeng yang berbeda dan juru okulasi yang sama. Setiap ulangan terdiri dari 35 tanaman contoh, sehingga terdapat 525 satuan percobaan.

Data sekunder diperoleh dari laporan manajemen, arsip kebun dan dokumentasi lainnya. Data sekunder yang diperoleh antara lain luas areal, curah hujan, iklim, konsesi dan tata guna lahan, keadaaan tanaman (umur tanam, populasi tanaman, jenis klon tanaman), struktur organisasi dan ketenagakerjaan (jumlah pekerja, keterampilan pekerja, dan standar hari kerja), peta lokasi, peta sebaran populasi, data produktivitas dari masing-masing klon yang ditanam, dan data sebaran populasi klon di tiap blok.

Data yang diperoleh akan dianalisis secara deskriptif dan kuantitatif. Analisis deskriptif dilakukan dengan menjelaskan hasil data berdasarkan perbandingan dengan data standar baku perusahaan. Analisis kuantitatif terhadap pengamatan persentase keberhasilan okulasi, tinggi tunas, kondisi batang bawah, dan waktu okulasi dianalisis menggunakan analisis ragam (uji F). Apabila hasil analisis ragam menunjukkan pengaruh nyata, analisis dilanjutkan dengan uji lanjut DMRT (Duncan Multiple Range Test) pada taraf $5 \%$ (Gomez dan Gomez, 2007).

\section{HASIL DAN PEMBAHASAN}

\section{Keadaan Umum}

Pelaksanaan pengamatan aspek khusus pada kegiatan magang dilakukan di areal pembibitan Perkebunan Karet. Keadaan iklim di kebun menurut klasifikasi Schmidt \& Ferguson termasuk ke dalam tipe iklim A (sangat basah) dengan kelembaban udara harian rata- rata \pm 75 $\%$ dan suhu rata-rata harian $30{ }^{\circ} \mathrm{C}$. Rata-rata curah hujan tahunan di kebun adalah $2377 \mathrm{~mm}$ tahun $^{-1}$ dengan rata-rata bulan basah (BB) 9.30 bulan dan bulan kering (BK) 1.10 bulan dalam setahun. Jenis tanah adalah Podsolik Merah Kuning dengan $\mathrm{pH}$ antara 6 - 7. Tanah di Perkebunan Karet memiliki kemampuan menahan air $(W H C)$ yang relatif rendah karena kandungan pasirnya yang relatif cukup tinggi.

Total luas areal pembibitan (nursery) di kebun adalah 16.50 ha yang terletak di Sub-Divisi I, divisi III Dolok Ulu. Klon karet yang dominan digunakan sebagai batang atas (entres) terdiri atas PB 260, PB 330, PB 340, DMI 11, DMI 13, dan DMI 35. Produktivitas masing-masing klon pada tahun 2013 diantaranya klon PB $2602474 \mathrm{~kg}$ $\mathrm{ha}^{-1}$, klon PB 330 sebesar $1376 \mathrm{~kg} \mathrm{ha}^{-1}$, klon PB 340 sebesar $1597 \mathrm{~kg} \mathrm{ha}^{-1}$, klon DMI 13 sebesar 2 $233 \mathrm{~kg} \mathrm{ha}^{-1}$ dan klon DMI 35 sebesar $2005 \mathrm{~kg} \mathrm{ha}^{-}$ 1 .

\section{Aspek Teknis}

Kegiatan teknis yaitu semua kegiatan yang berkaitan dengan budi daya tanaman karet. Penulis mengikuti kegiatan teknis sebagai karyawan harian lepas (KHL). Kegiatan ini bertujuan untuk memperoleh pengetahuan dan keterampilan tentang aspek teknik budi daya tanaman karet. Aspek teknis yang dilakukan oleh penulis pada proses magang di perkebunan PT 
BSRE hanya pada aspek pembibitan. Kegiatan teknis yang dilakukan yaitu pengecambahan benih dengan cara penyemaian, belajar okulasi, seleksi hasil okulasi, penyerongan (cut back), pewiwilan, seleksi bibit siap tanam, pengangkutan bibit, pengendalian gulma, dan pemancangan. Prestasi kerja yang dicapai penulis selama pelaksanaan kegiatan teknis di lapangan terdapat pada Tabel 1.

Tabel 1. Prestasi Kerja yang dicapai penulis, karyawan, dan standar kerja

\begin{tabular}{lccc}
\hline \multirow{2}{*}{ Kegiatan } & \multicolumn{2}{c}{ Prestasi kerja $\left(\mathrm{HK}^{-1}\right)$} \\
\cline { 2 - 4 } $\begin{array}{lcc}\text { Pembuatan bedengan semai dan } \\
\text { penyemaian bibit karet }\end{array}$ & Mahasiswa & Pekerja & Standar \\
Belajar okulasi & 35 pokok & 1.5 bedeng & 1 bedeng \\
Pewiwilan/penunasan bibit hasil okulasi & 5100 tanaman & 7500 pokok & 112 pokok \\
Seleksi bibit siap tanam & 79 tanaman & 300 tanaman & 4800 tanaman \\
Pengangkutan bibit siap tanam & 178 bibit & 250 bibit & 300 tanaman \\
Pembukaan okulasi pada kontrol I & 480 tanaman & 2005 tanaman & 1800 tanaman \\
Pengendalian gulma manual & 4 baris & 6 baris & 10 baris \\
Seleksi calon batang bawah (culiing) & 6 bedeng & 11.5 bedeng & 13 bedeng \\
Belajar membuat jendela okulasi & 35 pokok & 300 pokok & 112 pokok \\
Belajar membungkus okulasi & 35 pokok & 300 pokok & 112 pokok \\
Pengisian polibag dan pembongkaran & 50 polybag & 160 polybag & 160 polybag \\
persemaian benih & & & 1 ha \\
Pemancangan(pancang kepala) & 0.015 ha & 0.875 ha & 1 ha \\
Pemancangan (titik nol) & 0.875 ha & 0.875 ha & 7 ha \\
Pemancangan (pancang kepala) & 7 ha & 7 ha & 7 ha \\
Pemancangan (pancang batas) & 7 ha & 7 ha & \\
\hline
\end{tabular}

Secara umum prestasi kerja pekerja sudah mencapai standar yang ditentukan oleh perusahaan karena pekerja sudah memiliki pengalaman kerja yang cukup lama. Prestasi kerja penulis masih belum mencapai standar perusahaan karena penulis masih dalam tahap pengenalan dan belajar dalam melakukan pekerjaan di lapangan. Secara kuantitas pekerja sudah mencapai target perusahaan, tetapi secara kualitas hasil kerja masih kurang sesuai dengan kualitas hasil kerja yang diinginkan perusahaan. Hal ini disebabkan oleh kurangnya pengawasan dari mandor kerja. Solusi yang perlu dilakukan adalah dengan melakukan pengawasan dan pengarahan yang lebih intensif lagi serta memberikan pengertian kepada karyawan bahwa kualitas kerja juga perlu diperhatikan.

\section{Aspek Manajerial}

Asisten sub-divisi. Asisten Sub-Divisi memilki kewenangan dan tanggung jawab terhadap wilayah yang dikelolanya sesuai dengan ketetapan SOP lapangan PT BSRE. Tugas yang menjadi kewenangan Asisten SubDivisi adalah melakukan pengawasan dan memastikan seluruh kegiatan lapangan yang ada di wilayahnya secara rutin. Kegiatan sebagai pendamping asisten yang telah diikuti penulis selama magang di Sub-Divisi I Pondok Baru, Divisi III Dolok Ulu PT BSRE antara lain adalah memeriksa kegiatan penyadapan, mengawasi seluruh kegiatan perawatan di areal TBM dan TM, mengawasi kegiatan persiapan lahan dan penanaman di areal replanting, dan megikuti kegiatan apel pagi pukul 05.30 WIB bersama para mandor. Rincian kegiatan kerja yang diawasi adalah pelaksanaan penyadapan di Blok V-23, V26 dan W-26, pembibitan LCC di Blok W-23, pemancangan di Blok U-22, pembuatan parit isolasi batas kebun di Blok T-21, pembuatan reservoir, dan pengendalian gulma strip spraying di Blok W-23. Menurut penilaian penulis selama menjadi pendamping asisten kualitas kerja dan prestasi kerja para mandor di Sub-Divisi I Pondok Baru sudah baik. Hal ini ditunjukkan oleh kualitas hasil kerja yang dihasilkan dan tercapainya target kerja yang sudah rencanakan.

Mandor perawatan. Mandor perawatan memiliki kewenangan dan tanggung jawab dalam mengawasi pekerjaan perawatan yang dilaksanakan setiap sesuai pembagian kerjanya, memeriksa kehadiran para pekerja lepas atau FL, menyusun laporan dan rencana kerja, memastikan bahwa seluruh pekerjaan selesai sesuai prosedur, menjaga dan merawat inventaris peralatan kerja kebun setiap hari setelah selesai digunakan, dan berkewajiban hadir setiap hari pukul 05.30 WIB pada kegiatan apel/antrian pagi di kantor sub-divisi. Kegiatan pendampingan mandor perawatan yang diikuti oleh penulis 
adalah kegiatan pengawasan pengolahan lahan, pengendalian gulma TBM, pengendalian gulma (strip spraying), pemupukan TBM, pembibitan LCC, penunasan TBM, pemancangan, semprot daun, dan aplikasi stimulansia. Prestasi kerja yang dicapai penulis selama pelaksanaan kegiatan manjerial sebagai pendamping mandor perawatan dapat dilihat pada Tabel 2 .

Secara keseluruhan, kegiatan teknis budi daya tanaman karet sudah sesuai dengan standar perusahaan. Adapun permasalahan yang ditemukan selama menjadi pendamping mandor yaitu keterlambatan rotasi pekerjaan karena kondisi lingkungan, sehingga jadwal rotasi pekerjaan tidak sesuai dengan rencana kerja. Hal ini menyebabkan kualitas hasil pekerjaan kurang baik karena pekerja mengejar target yang lebih dari standar. Sebagai solusinya, perlu adanya rapat kerja secara intensif untuk menyusun jadwal ulang, sehingga pekerjaan yang belum dikerjakan dapat terkontrol.

Tabel 2. Prestasi kerja sebagai pendamping mandor perawatan

\begin{tabular}{lccc}
\hline \multirow{2}{*}{ Kegiatan } & \multicolumn{2}{c}{ Prestasi kerja (HK ${ }^{-1}$ ) } \\
\cline { 2 - 4 } & $\begin{array}{c}\text { Jumlah KHL yang } \\
\text { diawasi (orang) }\end{array}$ & $\begin{array}{c}\text { Luas areal yang } \\
\text { diawasi (ha) }\end{array}$ & $\begin{array}{c}\text { Lama kegiatan } \\
\text { (jam) }\end{array}$ \\
\hline Membongkar tunggul dan & 1 & 25 & 7 \\
penebangan pohon & & & 4 \\
Pengolahan lahan (Ripping 1) & 4 & 6.03 & 4 \\
Pengolahan lahan (Teraching) & 2 & 5.05 & 3.5 \\
Pengolahan Lahan (Ploughing) & 1 & 19 & 5.5 \\
Pemancangan & 6 & 12 & 5.5 \\
Pemancangan (pancang kepala) & 7 & 25 & 5 \\
Pembibitan LCC (Mucuna bracteata) & 10 & 0.25 & 5 \\
Penanaman stek LCC (Mucuna & 10 & 0.25 & 4.5 \\
bracteata) & & & 4.5 \\
Semprot sarang buaya & 5 & 1.5 & 3.5 \\
Semprot strip (Strip spraying) & 10 & 9.96 & 4.5 \\
Pemupukan dasar lahan pembibitan & 3 & 1 & 4.5 \\
Semprot sarang buaya & 5 & 1.5 & 2.5 \\
Semprot strip (Strip spraying) & 10 & 9.96 & 4.5 \\
Pemupukan TBM & 9 & 17.8 & 2 \\
Menunas & 6 & 14.25 & 1 \\
Semprot daun & 4 & 7 & - \\
Penimbangan hasil (Cup lumb) & 32 & & \\
\hline
\end{tabular}

Mandor penyadapan. Mandor sadap memiliki kewenangan dan tanggung jawab dalam mengawasi seluruh kegiatan penyadapan yang dikerjakan setiap hari. Permasalahan yang ditemui di lapangan saat menjadi pendamping Mandor Sadap antara lain kurang disiplinnya penyadap dalam kehadiran dan penyadapan yang masih kurang sesuai dengan aturan dan ketentuan yang berlaku. Banyak tanaman yang sudah rusak menyebabkan para penyadap melakukan penyadapan tidak sesuai dengan arahan mandor sadap. Hal-hal yang harus dilakukan oleh mandor untuk mengatasi masalah tersebut adalah memperketat pengawasan serta memberikan pengarahan agar penyadap lebih disiplin

Kegiatan pendampingan mandor sadap yang diikuti oleh penulis adalah kegiatan pengawasan penyadapan di Blok Y-25, Y-26, Z25, T-24, U-23, U-24, dan V-23. Prestasi kerja yang dicapai penulis selama pelaksanaan kegiatan manjerial sebagai pendamping mandor penyadapan dapat dilihat pada Tabel 3 .
Tabel 3. Prestasi kerja sebagai pendamping mandor penyadapan

\begin{tabular}{lccc}
\hline & \multicolumn{3}{c}{ Prestasi kerja $\left(\mathrm{HK}^{-1}\right)$} \\
\cline { 2 - 4 } Kegiatan & $\begin{array}{c}\text { Jumlah KHL } \\
\text { yang } \\
\text { diawasi } \\
\text { (orang) }\end{array}$ & $\begin{array}{c}\text { yang } \\
\text { diawasi } \\
\text { (ha) }\end{array}$ & $\begin{array}{c}\text { Lama } \\
\text { kegiatan } \\
\text { (jam) }\end{array}$ \\
\hline $\begin{array}{l}\text { Penyadapan } \\
\text { Latihan } \\
\text { penyadapan } \\
\begin{array}{l}\text { (Retraining) } \\
\text { Aplikasi } \\
\text { stimulansia }\end{array}\end{array}$ & 20 & 25 & 5.5 \\
\hline
\end{tabular}

Krani stasiun lateks. Krani Stasiun Lateks memiliki kewenangan dan tanggung jawab dalam memastikan bahwa penyadap mengerjakan seluruh kegiatan yang berhubungan dengan stasiun lateks sesuai prosedur yang ditetapkan, menyusun laporan produksi dan menyerahkannya ke kantor sub-divisi, melayani penimbangan lateks, cup lumb dan scrap dari para penyadap, menjaga kebersihan stasiun lateks termasuk tangki 
lateks dan peralatannya, membantu tugas seharihari krani sub-divisi, dan bertanggung jawab atas faktur kiriman lump sebagai bukti serah terima lateks dari lapangan ke pabrik. Penulis berperan sebagai pendamping krani stasiun lateks di stasiun lateks X-24 dan mepelajari cara menggunakan software penimbangan lateks. Pelaksanaan pengumpulan hasil sudah sesuai dengan prosedur yang ditetapkan perusahaan.

Permasalahan yang ditemukan selama menjadi pendamping krani stasiun cup lumb diantaranya keterlambatan penyadap datang ke stasiun cup lumb, keterlambatan mobil pengangkut hasil, serta penentuan potongan timbangan untuk kadar air. Hal ini menyebabkan terjadi selisih timbangan antara lapangan dan pabrik karena kandungan air dalam cup lumb sudah banyak keluar.

\section{Aspek Khusus}

Okulasi. Parameter yang diamati yaitu persentasi keberhasilan okulasi tiap klon untuk melihat kualitas dan potensi batang atas yang digunakan karena penggunaan benih untuk batang bawah di pembibitan menggunakan benih dengan klon campuran. Keberhasilan okulasi dapat diketahui dengan cara membuat cungkilan pada perisai mata okulasi di luar matanya. Apabila masih berwarna hijau berarti okulasi dinyatakan berhasil (Amypalupy 2010).

Pengamatan dilakukan pada kontrol ke-2 (42 hari setelah okulasi), sehingga persentasi keberhasilan okulasi dihitung berdasarkan jumlah okulasi yang hidup pada kontrol ke-2. Data persentase keberhasilan okulasi dari 5 klon yang diamati dapat dilihat pada Tabel 4.

Tabel 4. Persentase keberhasilan okulasi tiap klon

\begin{tabular}{|c|c|c|c|c|}
\hline Klon & Bedeng & $\sum$ Diokulasi & $\sum$ Okulasi hidup & $\%$ Keberhasilan okulasi \\
\hline \multirow[t]{3}{*}{ PB 260} & 1 & 309 & 263 & 85.11 \\
\hline & 2 & 312 & 275 & 88.14 \\
\hline & 3 & 323 & 275 & 85.14 \\
\hline Rata-rata & & 944 & 813 & $86.13 \mathrm{a}$ \\
\hline \multirow[t]{3}{*}{ PB 340} & 1 & 254 & 184 & 72.44 \\
\hline & 2 & 235 & 164 & 69.79 \\
\hline & 3 & 294 & 178 & 60.54 \\
\hline Rata-rata & & 783 & 526 & $67.59 \mathrm{bc}$ \\
\hline \multirow[t]{3}{*}{ PB 340} & 1 & 264 & 120 & 45.45 \\
\hline & 2 & 283 & 129 & 45.45 \\
\hline & 3 & 266 & 184 & 69.17 \\
\hline Rata-rata & & 813 & 433 & $53.36 \mathrm{~cd}$ \\
\hline \multirow[t]{3}{*}{ DMI 13} & 1 & 280 & 217 & 77.50 \\
\hline & 2 & 235 & 184 & 78.30 \\
\hline & 3 & 264 & 181 & 68.56 \\
\hline Rata-rata & & 264 & 181 & $74.79 \mathrm{ab}$ \\
\hline \multirow[t]{3}{*}{ DMI 35} & 1 & 274 & 163 & 59.49 \\
\hline & 2 & 274 & 112 & 40.88 \\
\hline & 3 & 258 & 115 & 44.57 \\
\hline Rata & & 806 & 390 & $48.31 d$ \\
\hline
\end{tabular}

Keterangan: Angka yang diikuti huruf yang berbeda pada kolom yang sama menandakan bahwa hasil uji f dengan nilai uji lanjut DMRT pada taraf $5 \%$ berbeda nyata. Sumber : Data hasil pengamatan lapang.

Hasil analisis data menunjukkan bahwa persentase keberhasilan okulasi pada 5 klon yang diamati berbeda nyata. Rata-rata persentase keberhasilan okulasi masing-masing klon bervariasi. Klon PB 260 memiliki persentasi keberhasilan okulasi tertinggi sebesar $86.13 \%$ dan persentase keberhasilan terendah yaitu pada klon DMI 35 sebesar 48.31\%. Penelitian yang dilaksanakan BPTP Jambi (2008), menunjukkan bahwa keberhasilan okulasi klon PB 260 dengan batang bawah GT 1 adalah $84 \%$ dan dengan batang bawah Avros 2037 adalah 83\%. Hal ini menunjukan bahwa klon batang atas PB 260 memilki kompatibilitas yang tinggi (Tabel 5).
Menurut Boerhendy (2003), perbedaan tingkat keberhasilan okulasi dapat disebabkan oleh 2 faktor yaitu: (1) perbedaan karakteristik jaringan mata tunas antar klon, sehingga suatu klon lebih mudah diokulasikan dari pada jenis lainnya, (2) perbedaan kompatibilitas antara jaringan batang atas dan batang bawah. Benih untuk batang bawah seharusnya berasal dari benih terpilih (propellegitim) yaitu benih yang diketahui pohon induknya. Klon anjuran untuk batang bawah adalah GT 1, PR 300, PR 228, AVROS 2037, LCB 1320, PB 260, BPM 24, PB 330 dan RRIC 100 (Boerhendhy 2012). Benih dari klon anjuran sulit didapatkan, oleh karena itu benih 
yang digunakan untuk batang bawah yaitu benih dari klon campuran (mix). Hal ini juga mempengaruhi keberhasilan okulasi yang kualitas batang bawahnya tidak merata.

Selanjutnya untuk melihat daya kompatibilitas dari masing-masing klon, maka dilakukan pengamatan terhadap tinggi tunas dalam polybag pada bulan ke-1 dan bulan ke-2 setelah dilakukan penyerongan (cut back). Hasil pengamatan dapat dilihat pada Tabel 5 .

Tabel 5. Pengamatan rata-rata tinggi tunas pada 5 klon yang diamati

\begin{tabular}{|c|c|c|c|c|c|}
\hline \multirow{2}{*}{ Klon } & \multirow{2}{*}{ Bedeng } & \multirow{2}{*}{$\sum$ Tanaman } & \multicolumn{2}{|c|}{ Tinggi tunas $(\mathrm{cm})$} & \multirow{2}{*}{ Pertumbuhan } \\
\hline & & & Bulan ke-1 & Bulan ke-2 & \\
\hline \multirow[t]{3}{*}{ PB 260} & 1 & 35 & 19.00 & 26.01 & 7.01 \\
\hline & 2 & 35 & 8.28 & 23.64 & 15.36 \\
\hline & 3 & 35 & 10.71 & 25.07 & 14.36 \\
\hline Rata-rata & & & $12.66 \mathrm{a}$ & $24.91 \mathrm{ab}$ & $12.25 \mathrm{a}$ \\
\hline \multirow{3}{*}{ PB 340} & 1 & 35 & 19.87 & 22.80 & 2.93 \\
\hline & 2 & 35 & 21.93 & 22.54 & 0.61 \\
\hline & 3 & 35 & 17.52 & 24.09 & 6.57 \\
\hline Rata-rata & & & $19.92 \mathrm{a}$ & $23.14 b$ & $3.36 \mathrm{~b}$ \\
\hline \multirow[t]{3}{*}{ PB 340} & 1 & 35 & 12.61 & 22.03 & 9.42 \\
\hline & 2 & 35 & 12.81 & 23.91 & 11.10 \\
\hline & 3 & 35 & 13.33 & 26.47 & 13.14 \\
\hline Rata-rata & & & $12.92 \mathrm{a}$ & $24.14 \mathrm{ab}$ & $11.22 \mathrm{a}$ \\
\hline \multirow[t]{3}{*}{ DMI 13} & 1 & 35 & 16.41 & 27.37 & 10.96 \\
\hline & 2 & 35 & 5.43 & 24.03 & 18.60 \\
\hline & 3 & 35 & 16.22 & 27.83 & 11.61 \\
\hline Rata-rata & & & $12.69 \mathrm{a}$ & $26.41 \mathrm{a}$ & $13.72 \mathrm{a}$ \\
\hline \multirow[t]{3}{*}{ DMI 35} & 1 & 35 & 21.03 & & \\
\hline & 2 & 35 & 12.60 & & \\
\hline & 3 & 35 & 4.44 & & \\
\hline Rata-rata & & & $12.69 \mathrm{a}$ & & \\
\hline
\end{tabular}

Keterangan: Angka yang diikuti huruf yang berbeda pada kolom yang sama menandakan bahwa hasil uji f dengan nilai uji lanjut DMRT pada taraf $5 \%$ berbeda nyata. Sumber: Data hasil pengamatan lapang

Berdasarkan hasil analisis data, rata-rata tinggi tunas pada 5 klon yang diamati pada bulan ke-1 tidak berbeda nyata tetapi pada bulan ke-2 rata-rata tinggi tunas berbeda nyata dan jika dilihat pertumbuhannya tidak berbeda nyata. Pada saat kegiatan magang memasuki bulan ke-4, tinggi tunas DMI 35 baru mencapai umur 1 bulan setelah penyerongan (cut back). Oleh karena itu, pengamatan tinggi tunas klon DMI 35 pada bulan ke-2 setelah penyerongan tidak teramati.

Hasil pengamatan pertumbuhan tinggi tunas hasil okulasi pada 5 klon yang diamati menunjukkan bahwa pertumbuhan tunas yang tertinggi yaitu pada klon DMI 13 sebesar 13.72 $\mathrm{cm}$ bulan $^{-1}$, tetapi tidak berbeda dengan klon PB 260 sebesar $12.25 \mathrm{~cm} \mathrm{bulan}^{-1}$ dan klon PB 340 sebesar $11.22 \mathrm{~cm}$ bulan $^{-1}$ sedangkan pertumbuhan tunas terendah yaitu pada klon PB 260 sebesar $3.36 \mathrm{~cm}$ bulan $^{-1}$. Pada umur 31 hari atau 1 bulan pertama (payung pertama) setelah penyerongan, pertumbuhan klon PB 330 memiliki pertumbuhan tunas tertinggi sebesar $19.78 \mathrm{~cm}$ bulan $^{-1}$ dan pada bulan ke-2 setelah penyerongan klon DMI 13 memiliki pertumbuhan tunas tertinggi sebesar $26.41 \mathrm{~cm}$ bulan $^{-1}$. Menurut penelitian Novalina (2009), menunjukkan bahwa panjang tunas hasil okulasi yang terbentuk pada umur 31 hari setelah tanam berkisar $8.90 \mathrm{~cm}$ sampai 19.20 $\mathrm{cm}$. Tinggi rendahnya tunas pertama (payung pertama) pada benih karet ini akan mempengaruhi perkembangan tunas kedua yang secara tidak langsung akan berpengaruh terhadap singkat atau lambatnya tanaman karet siap disadap (matang sadap). Waktu yang dibutuhkan untuk membentuk 1 payung tunas berkisar 60 hari. Hal ini diduga dipengaruhi oleh kompabilitas antara batang bawah dengan batang atas yang menyangkut faktor genetik masing-masing klon.

Kondisi batang bawah. Pengamatan ini dilakukan untuk menganalisis hubungan batang bawah terhadap keberhasilan okulasi tanaman karet. Batang bawah yang digunakan merupakan klon campuran, sedangkan untuk batang atas menggunakan klon PB 330. Pengamatan dilakukan pada juru okulasi yang sama untuk menyeragamkan kondisi tanaman yang diamati. Parameter yang diamati adalah keberhasilan okulasi pada pemeriksaan okulasi ke-2 (42 hari setelah okulasi). Hasil pengamatan keberhasilan okulasi pada kondisi batang bawah dapat dilihat pada Tabel 6 . 
Tabel 6. Pengamatan kondisi batang bawah terhadap persentase keberhasilan okulasi

\begin{tabular}{lcc}
\hline $\begin{array}{c}\text { Kondisi Batang } \\
\text { Bawah }\end{array}$ & $\sum$ diokulasi & $\begin{array}{c}\text { \% Keberhasilan } \\
\text { Okulasi }\end{array}$ \\
\hline \multirow{3}{*}{ Flush } & 35 & 62.86 \\
& 35 & 40.00 \\
\hline Rata-rata & 35 & 62.86 \\
\hline Dorman & 35 & $55.24 \mathrm{~b}$ \\
& 35 & 88.57 \\
Rata-rata & 35 & 62.86 \\
Keterangan: & Angka yang diikuti huruf yang berbeda pada \\
& kolom yang sama menandakan bahwa hasil \\
& uji f dengan uji lanjut DMRT pada taraf 5\% \\
& berbeda nyata. Sumber: Data \\
& pengamatan lapang
\end{tabular}

Hasil analisis data kondisi batang bawah menunjukkan bahwa persentase keberhasilan okulasi pada kondisi batang bawah yang sedang dorman dan flush berbeda nyata. Kondisi daun batang bawah yang sedang dorman (81.90\%) mempunyai keberhasilan okulasi yang lebih baik dari pada kondisi daun batang bawah yang sedang flush (55.24). Kondisi daun batang bawah yang sedang dorman dicirikan oleh kulit batang yang tidak lengket karena getah yang keluar sedikit, sehingga pertautan batang atas dan batang bawah lebih sempurna jika dibandingkan saat kondisi daun batang bawah yang sedang flush. Hal ini sesuai dengan teori yang menyebutkan bahwa kondisi tunas batang bawah yang baik untuk okulasi yaitu tunas batang bawah dalam keadaan tidur (dorman) atau daun tua (Amypalupy, 2012). Selain itu teori lain menyebutkan bahwa kondisi terbaik batang bawah dalam kegiatan okulasi yaitu pada fase pertumbuhan yang optimum, kambium aktif, sehingga memudahkan dalam pengupasan dan proses merekatnya mata tempel ke batang bawah (Prastowo dan Roshetko, 2006).

Teori kendali umpan balik menjelaskan bahwa semakin meningkatnya transpirasi karena pertumbuhan dan perkembangan tunas-tunas muda, luas permukaan transpirasi bertambah dengan cepat sedemikian rupa sehingga akar tidak mampu lagi mengimbanginya dengan suplai air yang cukup. Akibatnya terjadi cekaman air sehingga ujung-ujung tumbuhan pada bagian tunas menjadi dorman. Pada keadaan tersebut daun masih tetap berfungsi, tetapi karena tunas tidak lagi menjadi sink (penampung), fotosintat banyak dialirkan ke akar, dengan akibat akar tumbuh dan beramifikasi lagi. Pada giliran air berikut hara mineral dan hormon (terutama sitokinin yang diproduksi diakar) dialirkan lagi ke bagian atas tumbuhan, tunas kuncup yang dorman terpicu lagi, tunas yang kuncup mulai pecah, flushing, dan daun berkembang (Akyas, 2011). Hal ini menjelaskan bahwa pada kondisi batang flush terdapat aliran air dan asimilat yang dihasilkan tanaman untuk pertumbuhan daun sehingga getah akan banyak keluar dan akan menyebabkan lengketnya kulit pada kayu. Kondisi tersebut menyebabkan pertautan mata tunas dan kayu batang bawah tidak sempurna karena kecenderungan bahwa semakin muda daun yang terdapat pada batang bawah, maka semakin banyak getah yang keluar dari batang tanaman sehingga akan menyulitkan pada saat pembuatan jendela okulasi. Hal ini menyebabkan persentase keberhasilan okulasi pada kondisi batang bawah yang flush rendah.

Waktu okulasi. Pengamatan dilakukan pada 3 waktu yaitu pukul 07.00-09.00, 09.0011.00, dan 11.00-13.00 WIB pada 3 bedeng yang berbeda. Keberhasilan okulasi dilihat pada pemeriksaan ke-2 (42 hari setelah okulasi). Adapun hasil pengamatan persentase keberhasilan okulasi berdasarkan waktu dapat dilihat pada Tabel 7

Berdasarkan hasil analisis data terhadap pengamatan waktu okulasi, persentase keberhasilan okulasi pada 3 kondisi waktu okulasi tidak berbeda nyata. Hasil pengamatan waktu okulasi pada pukul 07.00-09.00 WIB menunjukkan rata-rata persentase keberhasilan okulasi sebesar $74.39 \%$, pada pukul $09.00-11.00$ WIB menunjukkan rata-rata persentase keberhasilan okulasi sebesar $67.13 \%$ dan pada pukul 11.00-13.00 WIB menunjukkan rata-rata persentase keberhasilan okulasi sebesar $60.92 \%$. Berdasarkan hasil pengamatan tersebut memberikan informasi bahwa semakin siang waktu okulasi, maka persentase keberhasilan okulasi semakin rendah. Hal ini sesuai dengan teori yang menyebutkan bahwa waktu terbaik untuk pelaksanaan okulasi adalah pada pagi hari, antara pukul 07.00-11.00 pagi, karena pada saat tersebut tanaman sedang aktif berfotosintesis sehingga kambium tanaman juga dalam kondisi aktif dan optimum. Pelaksanaan okulasi diatas pukul 12.00 siang kurang baik karena kondisi daun mulai layu dan kualitas entres sudah menurun (Prastowo dan Roshetko, 2006).

Tabel 7. Hasil pengamatan perbedaan waktu okulasi terhadap persentase keberhasilan okulasi

\begin{tabular}{cccc}
\hline Waktu okulasi & $\sum$ Okulasi & $\sum$ Okulasi hidup & $\%$ Keberhasilan \\
\hline
\end{tabular}




\begin{tabular}{|c|c|c|c|c|}
\hline & & (pohon) & (pohon) & okulasi \\
\hline \multirow[t]{3}{*}{$07.00-09.00$} & 1 & 452 & 325 & 71.90 \\
\hline & 2 & 441 & 337 & 76.42 \\
\hline & 3 & 457 & 342 & 74.84 \\
\hline Rata-rata & & 1350 & 1004 & $74.39 \mathrm{a}$ \\
\hline \multirow[t]{3}{*}{$09.00-11.00$} & 1 & 470 & 321 & 68.30 \\
\hline & 2 & 440 & 295 & 67.05 \\
\hline & 3 & 474 & 313 & 66.03 \\
\hline Rata-rata & & 1384 & 929 & $67.13 a$ \\
\hline \multirow[t]{3}{*}{$11.00-13.00$} & 1 & 459 & 301 & 65.58 \\
\hline & 2 & 458 & 268 & 58.52 \\
\hline & 3 & 474 & 278 & 58.65 \\
\hline Rata-rata & & 1391 & 847 & $60.92 \mathrm{a}$ \\
\hline
\end{tabular}

Keterangan : Angka yang diikuti huruf yang berbeda pada kolom yang sama menandakan bahwa hasil uji $\mathrm{f}$ dengan uji lanjut DMRT pada taraf $5 \%$ berbeda nyata. Sumber : Data hasil pengamatan lapang di PT BSRE

Kondisi suhu terbaik untuk pertumbuhan kalus adalah antara 21-29.51 ${ }^{\circ} \mathrm{C}$. Apabila temperatur $>29.51{ }^{0} \mathrm{C}$ dapat menimbulkan kerusakan pada pembentukan kalus, sedangkan bila temperatur $<21{ }^{\circ} \mathrm{C}$ akan memperlambat pembentukan kalus. Pembentukan kalus memerlukan kelembaban yang tinggi. Apabila kelembaban rendah dapat menimbulkan kekeringan yang dapat menyebabkan sel-sel pada pertautan okulasi mati sehingga dapat menghalangi pembentukan kalus (Robbyana, 2002). Kondisi suhu di kebun PT BSRE pada pagi hari rata-rata $26{ }^{\circ} \mathrm{C}$ dan pada siang hari dengan intensitas cahaya yang tinggi dapat mencapai rata-rata $33{ }^{\circ} \mathrm{C}$. Intensitas cahaya matahari yang tinggi pada siang hari dan kondisi suhu tinggi akan mempengaruhi proses okulasi. Oleh karena itu, okulasi sebaiknya dilakukan pada waktu pagi hari atau sore hari pada saat intensitas cahaya matahari rendah dan kondisi suhu cenderung rendah.

\section{KESIMPULAN}

Kegiatan magang secara umum dapat dijadikan acuan tentang aspek teknis maupun aspek manajerial yang dilakukan di lapangan. Mahasiswa mendapatkan pemahaman tentang pengelolaan tanaman karet dengan baik. Selain itu mahasiswa dapat memahami tentang aspek manajerial perkebunan dengan baik, sehingga mahasiswa dapat melihat relevansi dan kesesuaian antara proses pendidikan dengan lapangan pekerjaan.

Secara khusus, aspek pembibitan pada tanaman karet dipengaruhi oleh kegiatan okulasi yang dilakukan. Okulasi yang dilakukan di perkebunan adalah okulasi hijau. Persentase keberhasilan okulasi dipengaruhi oleh beberapa hal diantaranya kondisi batang bawah, kompatibilitas klon yang digunakan sebagai batang atas (mata tunas) dan waktu okulasi.
Kondisi batang bawah yang sedang dorman $(81.90 \%)$ mempunyai persentase keberhasilan okulasi lebih tinggi dari pada kondisi batang bawah yang sedang flush (55.24\%). Persentasi keberhasilan okulasi pada 5 klon yang diamati berbeda nyata. Persentasi keberhasilan okulasi tertinggi yaitu klon PB 260 sebesar $86.13 \%$ dengan rata-rata pertumbuhan tunas $12.25 \mathrm{~cm}$ bulan $^{-1}$ dan persentase keberhasilan terendah yaitu pada klon DMI 35 sebesar $48.31 \%$. Hal ini menunjukan bahwa klon batang atas PB 260 memilki kompatibilitas yang tinggi. Waktu yang terbaik untuk melakukan okulasi pada tanaman karet adalah pada pukul 07.00-09.00 WIB karena transpirasi dan intensitas cahaya matahari rendah. Cahaya yang terlampau kuat akan mengurangi daya tahan batang entres.

\section{DAFTAR PUSTAKA}

Akyas, A,M. 2011. Dasar Teknologi (Biologi) Pengendalian Panen Mangga. Bandung (ID): Universitas Padjadjaran.

Amypalupy, K. 2012. Produksi Bahan Tanam Karet. Sumatera Selatan (ID): Balai Penelitian Karet Sembawa.

Anwar, C. 2007. Manajemen dan Teknologi Budi daya Karet. Makalah disampaikan pada Pelatihan Tekno Ekonomi Agribisnis Karet. Jakarta.

Balai Penelitian Sembawa. 2009. Pengelolaan Bahan Tanam Karet. Palembang (ID): Pusat Penelitian Karet. Balai Penelitian Sembawa.

[BPTPJ] Balai Pengkajian Teknologi Pertanian Jambi. 2007. Teknik Pembibitan dan Budi Daya Karet Unggul di Provinsi Jambi. 
Boerhendhy, I., Amypalupy K. 2010. Optimalisasi produktivitas karet melalui penggunaan bahan tanaman, pemeliharaan, sistem eksploitasi dan peremajaan tanaman . J. Litbang Pert. 30(2):23-30.

Boerhendhy, I. 2012. Pembangunan Batang Bawah. Sumatera Selatan (ID): Balai Penelitian Karet Sembawa.

Boerhendhy, I. 2013. Prospek perbanyakan bibit karet unggul dengan teknik okulasi dini. J. Litbang Pert. 32(2): 85-90.

[Ditjenbun]. Direktorat Jenderal Perkebunan. 2013. Produksi, Luas Areal dan Produktivitas Perkebunan di Indonesia.

Gomez, K.A., Gomez, A.A. 2007. Prosedur Statistika Untuk Penelitian Pertanian. Sjamsudin, E., Baharsjah, J.S, penerjemah. Jakarta (ID): UI Press.
Terjemah dari : Statistical Procedur for Agricultural Research. Ed ke-2.

Novalina. 2009. Pewarisan beberapa karakter kualitatif pada tanaman karet. $J$. Agronomi. 13(1):17-20.

Prastowo, N., Roshetko, J.M. 2006. Tehnik Pembibitan dan Perbanyakan Vegetatif Tanaman Buah. World Agroforestry Centre (ICRAF) dan Winrock International, Bogor. P.100

Robbyana, Y. 2002. Pembibitan tanaman karet (Hevea brasiliensis Muall. Arg) di kebun Batulawang PTPN VII (Persero) Ciamis, Jawa Barat [skripsi]. Bogor (ID): Institut Pertanian Bogor.

Setiawan, D.H., Andoko, A. 2008. Petunjuk Lengkap Budi Daya Karet. Jakarta (ID): AgroMedia Pustaka. 